\title{
Gelsolin-Cu/ZnSOD interaction alters intracellular reactive oxygen species levels to promote cancer cell invasion
}

\author{
Lalchhandami Tochhawng ${ }^{1}$, Shuo Deng ${ }^{1}$, Ganesan Pugalenthi ${ }^{3}$, Alan Prem \\ Kumar ${ }^{2,4,5,6,7}$, Kiat Hon Lim ${ }^{8}$, Tuan Zea Tan ${ }^{4}$, Henry Yang ${ }^{4}$, Shing Chuan Hooi ${ }^{1}$, Yaw \\ Chong Goh ${ }^{9,10}$, Sutherland K. Maciver ${ }^{11}$, Shazib Pervaiz ${ }^{1,12,13,14}$ and Celestial T. Yap ${ }^{1,5}$ \\ ${ }^{1}$ Department of Physiology, Yong Loo Lin School of Medicine, National University of Singapore, Singapore \\ 2 Department of Pharmacology, Yong Loo Lin School of Medicine, National University of Singapore, Singapore \\ ${ }^{3}$ Bioinformatics Group, Bioscience Core Laboratory, King Abdullah University of Science and Technology (KAUST), Kingdom \\ of Saudi Arabia \\ ${ }^{4}$ Cancer Science Institute of Singapore, National University of Singapore, Singapore \\ ${ }^{5}$ National University Cancer Institute, Singapore \\ ${ }^{6}$ Curtin Health Innovation Research Institute, Biosciences Research Precinct, School of Biomedical Sciences, Faculty of \\ Health Sciences, Curtin University, WA, Australia \\ 7 Department of Biological Sciences, University of North Texas, Denton, TX, USA \\ ${ }^{8}$ Department of Pathology, Singapore General Hospital, Singapore \\ ${ }^{9}$ Department of General Surgery, Singapore General Hospital, Singapore \\ 10 Department of General Surgery, Mount Elizabeth Hospital, Singapore \\ ${ }^{11}$ Centre for Integrative Physiology, University of Edinburgh, United Kingdom \\ ${ }^{12}$ School of Biomedical Sciences, Faculty of Health Sciences, Curtin University, Perth, Western Australia \\ 13 NUS Graduate School for Integrative Sciences and Engineering, National University of Singapore, Singapore \\ 14 Singapore-MIT Alliance, Singapore \\ Correspondence to: Celestial T. Yap, email: celestial_therese_yap@nuhs.edu.sg \\ Shazib Pervaiz, email: phssp@nus.edu.sg
}

Keywords: invasion, gelsolin, cytoskeleton, Cu/ZnSOD, ROS, antioxidant

Received: December 21,2015 Accepted: June 28, $2016 \quad$ Published: July 06, 2016

\section{ABSTRACT}

The actin-binding protein, gelsolin, is a well known regulator of cancer cell invasion. However, the mechanisms by which gelsolin promotes invasion are not well established. As reactive oxygen species (ROS) have been shown to promote cancer cell invasion, we investigated on the hypothesis that gelsolin-induced changes in ROS levels may mediate the invasive capacity of colon cancer cells.

Herein, we show that increased gelsolin enhances the invasive capacity of colon cancer cells, and this is mediated via gelsolin's effects in elevating intracellular superoxide $\left(\mathrm{O}_{2}{ }^{-}\right)$levels. We also provide evidence for a novel physical interaction between gelsolin and $\mathrm{Cu} / \mathrm{ZnSOD}$, that inhibits the enzymatic activity of $\mathrm{Cu} / \mathrm{ZnSOD}$, thereby resulting in a sustained elevation of intracellular $\mathrm{O}_{2}{ }^{--}$. Using microarray data of human colorectal cancer tissues from Gene Omnibus, we found that gelsolin gene expression positively correlates with urokinase plasminogen activator (UPA), an important matrix-degrading protease invovled in cancer invasion. Consistent with the in vivo evidence, we show that increased levels of $\mathrm{O}_{2}{ }^{-}$induced by gelsolin overexpression triggers the secretion of uPA. We further observed reduction in invasion and intracellular $\mathrm{O}_{2}{ }^{-}$- levels in colon cancer cells, as a consequence of gelsolin knockdown using two different siRNAs. In these cells, concurrent repression of $\mathrm{Cu}$ / ZnSOD restored intracellular $\mathrm{O}_{2}{ }^{-}-$levels and rescued invasive capacity. 


\section{Our study therefore identified gelsolin as a novel regulator of intracellular $\mathrm{O}_{2}{ }^{--}$in cancer cells via interacting with $\mathrm{Cu} / \mathrm{ZnSOD}$ and inhibiting its enzymatic activity. Taken together, these findings provide insight into a novel function of gelsolin in promoting tumor invasion by directly impacting the cellular redox milieu.}

\section{INTRODUCTION}

Metastasis accounts for $90 \%$ of solid tumor deaths worldwide [1]. Amongst other factors involved in metastasis, invasion of tissues by cancer cells is a major determinant and the initial step of metastasis. Through attachment to and subsequent degradation of the extracellular matrix (ECM), loss of intercellular adhesion, enhanced cell motility and resistance to death, cancer cells acquire invasive capacity thereby resulting in metastatic spread $[2,3]$. Central to cancer cell migration and invasion is the regulation of the actin cytoskeleton. The gelsolin superfamily of proteins, in particular gelsolin, is an important regulator of the actin cytoskeleton [4]. Owing to its regulation of actin filaments via capping and severing, gelsolin is believed to promote cell migration and invasion. Gelsolin has been shown to translocate to the plasma membrane and associate with the actin cytoskeleton. Due to this association, the ratio between actin filament and monomeric actin is significantly reduced, which promotes cell migration [5]. The critical involvement of gelsolin in cells' invasive capacity is further corroborated by the findings that cell invasion associated with supervillin, another member of the gelsolin superfamily, also involves the intermediacy of gelsolin [6]. Multiple cell survival/ proliferation pathways have been implicated in gelsolininduced migration and invasion, namely Ras-PI3K-Rac network [7], epidermal growth factor (EGF) [8] and erbB2/EGFR (epidermal growth factor receptor) [9] pathways.

Cellular protrusions such as lamellipodia, filopodia and invadopodia are critical invasive structures that form the leading edge of invading cells in cancer [10]. Gelsolin has been shown to play an important role in the EGFinduced cell migration by participating in lamellipodia formation [8]. Gelsolin has also been shown to be important for the formation of podosomes in osteoclasts [11], the equivalent structure of invadpodia in noncancer cells. The role of gelsolin in cellular protrusions can therefore be attributed to its regulation of the actin cytoskeleton. Invasive front in cancer cells are enriched with proteases such as the matrix metalloproteinases (MMPs) and the urokinase plaminogen activator (uPA) that aid in the degradation of the ECM $[12,13]$. We have previously reported that gelsolin overexpression enhances the production and secretion of uPA, thereby promoting invasion in colon cancer cells [14]. Our finding makes it tempting to speculate a critical role of gelsolin in proteolysis at the invasive front of cancer cells. In addition, it also points to an aspect of gelsolin which may be distinct from its actin regulation. The molecular mechanism by which gelsolin contributes to protease secretion remains poorly understood.

Reactive oxygen species (ROS) are chemically active molecules formed by the incomplete reduction of oxygen $\left(\mathrm{O}_{2}\right)$. Superoxide $\left(\mathrm{O}_{2}^{-}{ }^{-}\right)$, the precursor ROS is generated through enzymatic action of NADPH oxidase (Nox) or as a metabolic by-product of mitochondrial respiration. Subsequent reactions can give rise to the formation of other types of ROS such as hydrogen peroxide $\left(\mathrm{H}_{2} \mathrm{O}_{2}\right)$, hydroxyl radical ( $\left.\mathrm{OH}\right)$ and hypochlorous acid (HOCl). Under normal physiological conditions, redox homeostasis is maintained by the efficient cellular antioxidant systems [15]. Whereas, overwhelming oxidative stress is invariably associated with cell and tissue damage and/or death, there is accumulating evidence to implicate mild oxidative stress with cellular proliferation, growth and survival. In this regard, an imbalance between ROS production and anti-oxidant defense mechanisms has been shown to promote cell transformation and oncogenesis $[16,17]$. In fact, the myriad of signaling networks engaged by a pro-oxidant cellular milieu also provides the cells with the ability to migrate and invade, thereby favoring the progression of the disease [18]. Of note, there is recent evidence to implicate ROS-mediated regulation of the actin cytoskeleton dynamics in enhanced migration and invasion $[19,20]$. For example, intracellular $\mathrm{O}_{2}^{-}$is implicated in the small GTPase Rac1 mediated increase in actin polymerization. Pharmacological inhibition of intracellular ROS production with the Nox inhibitor diphenyleneiodonium (DPI), as well as the use of ROS scavengers such as manganese (III) tetrakis (1-methyl-4-pyridyl) porphyrin (MnTMPyP), abrogates actin filament elongation [21], thus suggesting the involvement of ROS in actin cytoskeletal dynamics. Furthermore, studies have also indicated that the actin cytoskeleton may initiate ROS generation, actin assembly was shown to enhance $\mathrm{O}_{2} \cdot$ production in eosinophils [22]. Stabilization of the Nox complex as well as recruitment of Nox subunits are also known to be influenced by the actin cytoskeletal proteins [23-25]. These findings provide testimony that, in addition to providing structural support, actin and its associated proteins may be engaged in ROS generation that promotes cancer cell invasion. Stimulated by these findings, here we hypothesized that gelsolin, a key actin regulatory protein, may contribute to the control of ROS levels in cancer cells. In this study, we provide evidence that the expression of gelsolin promotes invasion via mechanisms that involve an increase in intracellular $\mathrm{O}_{2}-$ in HCT116 colon cancer cells. Gelsolin suppresses the enzymatic activity of $\mathrm{Cu} / \mathrm{ZnSOD}$, thereby resulting in an accumulation of $\mathrm{O}_{2}-$ in the cells. Bioinformatic analysis 
and in situ approaches reveal the existence of a proteinprotein interaction between gelsolin and $\mathrm{Cu} / \mathrm{ZnSOD}$ that might account for the inhibition of the enzymatic activity. Thus, our findings provide a novel mechanism by which gelsolin mediates colon cancer cell invasion via modulating intracellular $\mathrm{O}_{2}^{--}$levels.

\section{RESULTS}

\section{Intracellular $\mathrm{O}_{2}^{--}$levels are modulated by gelsolin expression in cells}

We first sought to determine if gelsolin affects intracellular levels of ROS such as $\mathrm{O}_{2}^{-{ }^{-}}, \mathrm{H}_{2} \mathrm{O}_{2}, \mathrm{OH}$ and $\mathrm{HOCl}$. Using the chemiluminescent based lucigenin assay and the cell permeable dihydroethidium (DHE) dye, we assessed the changes in intracellular $\mathrm{O}_{2}{ }^{--}$levels with increased expression of gelsolin. Under normal growth conditions, the level of $\mathrm{O}_{2}{ }^{--}$was significantly elevated in cells stably overexpressing gelsolin (C1 and C8 cells) when compared to control cells stably transfected with the empty vector (Figures 1A \& S1A). Furthermore, siRNA mediated gene silencing of gelsolin in HCT116, RKO, HeLa and HepG2 cells resulted in a significant decrease in intracellular $\mathrm{O}_{2}{ }^{-}$levels (Figures $1 \mathrm{~B}, \mathrm{~S} 1 \mathrm{~B} \& \mathrm{C}$ ). Taken together, these data provide evidence to link gelsolin expression to an increase in intracellular $\mathrm{O}_{2}{ }^{--}$levels.

Previous studies have shown that several ROS including $\mathrm{H}_{2} \mathrm{O}_{2}, \mathrm{OH}$ and $\mathrm{HOCl}$ can oxidize 5-(and-6)chloromethyl-2',7'-dichlorodihydrofluorescein diacetate acetyl ester (CM-H DCFDA) [26-29]. Hence, gelsolin was depleted in several cancer cell lines including HCT116, RKO, Caco-2, DLD-1, HeLa and HepG2 and CM- $\mathrm{H}_{2}$ DCFDA oxidation assay was performed. However, there was no significant change in $\mathrm{CM}-\mathrm{H}_{2} \mathrm{DCFDA}$ intensity between gelsolin-knockdown and the control siRNA-treated cells (Figure S2A). This indicates that gelsolin is minimally involved in modulating $\mathrm{H}_{2} \mathrm{O}_{2}, \mathrm{OH}$ and $\mathrm{HOCl}$ levels in these cancer cells. In addition, the Amplex Red $\mathrm{H}_{2} \mathrm{O}_{2}$ assay was used to detect $\mathrm{H}_{2} \mathrm{O}_{2}$ levels
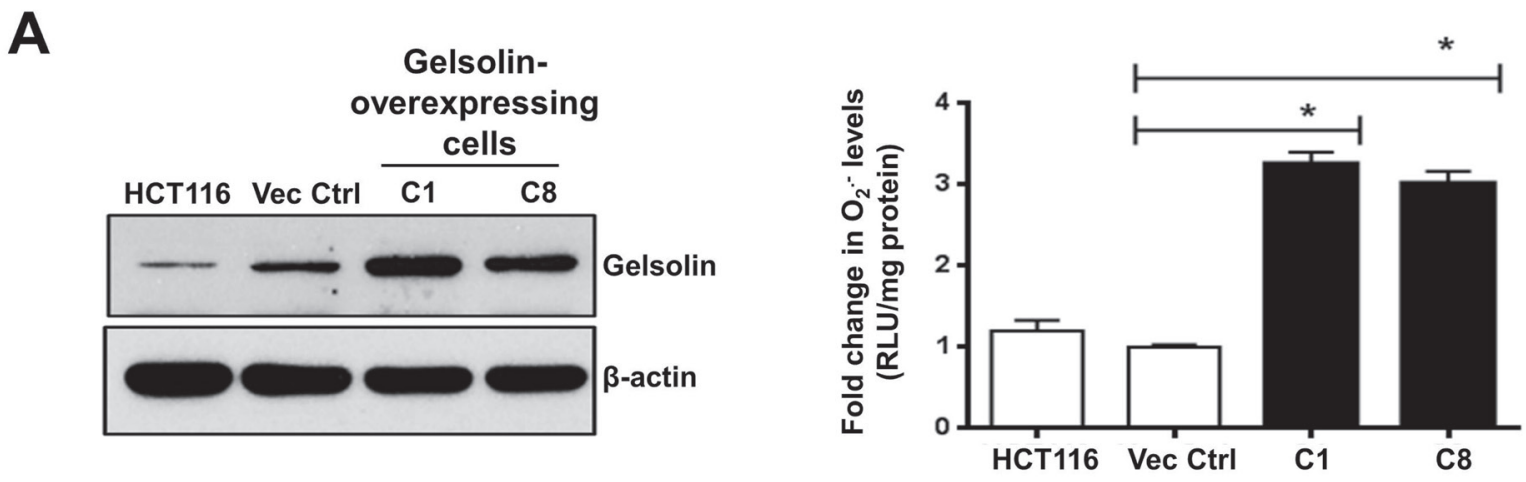

B

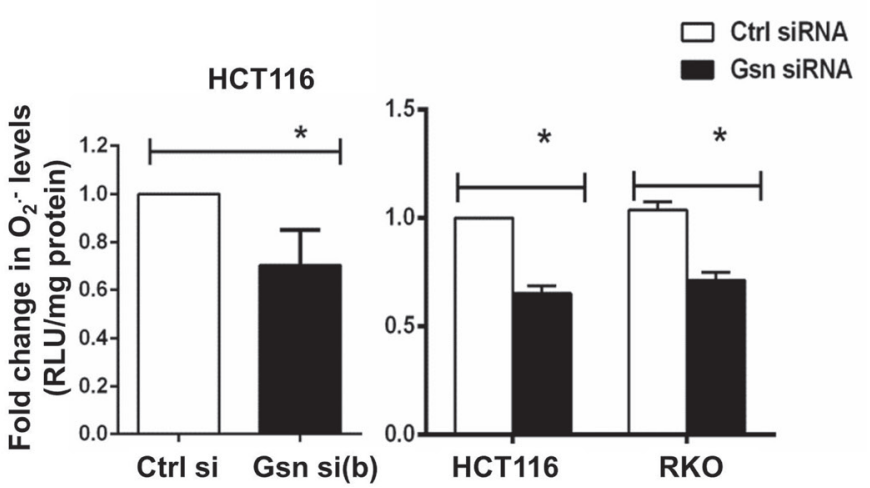

Figure 1: Gelsolin modulates intracellular superoxide $\left(\mathrm{O}_{2}^{--}\right)$levels. (A) Left panel: Western blot showing overexpression of gelsolin in HCT116 cells. Right panel: Intracellular $\mathrm{O}_{2}^{-}$levels were measured using the chemiluminescent-based lucigenin assay. Gelsolinoverexpressing cells (C1\&C8) show significantly higher levels of $\mathrm{O}_{2}{ }^{-}$when compared to the empty vector control cells. (B) Left panel: Western blot showing gelsolin-knockdown in HCT116 and RKO cells using two different siRNAs (Gsn si (b) \& Gsn si) targeting gelsolin in HCT116 and a single siRNA (Gsn si) in RKO cells. Right panel: Silencing of gelsolin in HCT116 and RKO cells results in decreased levels of $\mathrm{O}_{2}-$ when compared to the control siRNA. $\mathrm{O}_{2}-$ data shown are mean $\pm \mathrm{SD}$ of at least three independent experiments. ${ }^{*}$ p-value $<0.05$ versus controls using a two tailed Student's $t$-test. Values (mean $\pm \mathrm{SD}$ ) are expressed as fold over the empty vector control or the control siRNA, which is arbitrarily set to one. The western blot gel pictures are representative images from three independent experiments. 
in gelsolin-overexpressing cells. The Amplex Red reagent reacts with $\mathrm{H}_{2} \mathrm{O}_{2}$ resulting in a red fluorescent oxidation product which could be assayed fluorometrically. Again, no significant difference was observed in $\mathrm{H}_{2} \mathrm{O}_{2}$ levels when gelsolin expression was increased, compared to the empty vector transfected cells (Figure S2B). Taken together, these data suggest that gelsolin overexpression may specifically modulate only the levels of intracellular $\mathrm{O}_{2}{ }^{--}$.

\section{Gelsolin modulates $\mathrm{O}_{2}^{--}$levels by suppressing $\mathrm{Cu} /$ ZnSOD activity}

Antioxidants play important roles in maintaining the cellular redox homeostasis, therefore, abnormal fluctuations in the antioxidant system significantly alters the ROS-antioxidant balance resulting in redox dyshomeostasis [30]. An important determinant of increased $\mathrm{O}_{2}^{--}$levels in cells is the loss of enzymatic activity of the antoxidant $\mathrm{Cu} / \mathrm{ZnSOD}$ [31]. As such, we questioned whether the increase in intracellular $\mathrm{O}_{2}^{--}$upon overexpression of gelsolin was a function of a compromise in the enzymatic activity of $\mathrm{Cu} / \mathrm{ZnSOD}$. To assess that, SOD activity was first measured in total cell lysate (this is the combined enzymatic activities of the two SOD isoforms , $\mathrm{Cu} / \mathrm{ZnSOD}$ and MnSOD). Indeed, total SOD activity was significantly lower in the two cell lines overexpressing gelsolin, (C1 and $\mathrm{C} 8)$, compared to the empty vector transfected and wild-type HCT116 cells (Figure 2A). Similarly, depletion of endogenous gelsolin expression in wild-type HCT116 results in higher total SOD activity, relative to the control siRNA transfected cells (Figure 2B).

In order to identify the SOD isoform targeted by gelsolin, we performed subcellular fractionation experiment that separates the cytosol from intact mitochondria. $\mathrm{Cu} / \mathrm{ZnSOD}$ and MnSOD activities were assayed from the respective fractions. The validity of our fractionation was confirmed by the presence of $\mathrm{Cu} / \mathrm{ZnSOD}$ and GAPDH in the cytosol and MnSOD and VDAC in the mitochondrial fractions, whilst $\beta$-actin was used as the internal loading control for both fractions (Figure 2C \& 2D). Gelsolin-overexpressing $\mathrm{C} 1$ and $\mathrm{C} 8$ cells displayed lower $\mathrm{Cu} / \mathrm{ZnSOD}$ activity compared to empty vector control and wild-type HCT116 cells (Figure 2E), whereas $\mathrm{Cu} / \mathrm{ZnSOD}$ activity was significantly elevated following gelsolin knockdown in both HCT116 and C1 cells (Figure 2F). However, MnSOD activity was only minimally affected by the modulation of gelsolin expression as shown in Figure $2 \mathrm{G} \& 2 \mathrm{H}$. These results indicate that changes in gelsolin expression alter $\mathrm{Cu} / \mathrm{ZnSOD}$ activity but not MnSOD activity, and therefore the reduction of total SOD activity observed in figure $2 \mathrm{~A}$ is mainly accounted by the loss of $\mathrm{Cu} / \mathrm{ZnSOD}$ activity. It should be pointed out that changes in enzymatic activites could be influenced by protein expression; however the protein levels of both $\mathrm{Cu}$ / $\mathrm{ZnSOD}$ and MnSOD were not affected upon modulation of gelsolin expression (Figure 2C \& 2D).

\section{In silico analysis of gelsolin and $\mathrm{Cu} / \mathrm{ZnSOD}$ interaction}

In our attempt to explore how gelsolin suppresses $\mathrm{Cu} / \mathrm{ZnSOD}$ activity, we tested the possibility of a proteinprotein interaction between gelsolin and $\mathrm{Cu} / \mathrm{ZnSOD}$. Docking analysis using PatchDock was performed between gelsolin (PDB: 3FFN, chain A) [32] and $\mathrm{Cu}$ / ZnSOD (PDB: 1PU0 Chain A) [33], which suggested the presence of a direct interaction between gelsolin and $\mathrm{Cu} / \mathrm{ZnSOD}$ (Figure S3A). In addition, we identified the amino acid residues involved in the interaction (Figure $3 \mathrm{~A}-\mathrm{C}$ ), which also provided evidence that the $\mathrm{C}$-terminus of gelsolin is important in its interaction with $\mathrm{Cu} / \mathrm{ZnSOD}$ (Figure 3B). The amino acid residues 736, 737, 739 and 752 of gelsolin were predicted to form polar bonds with the amino acid residues 68, 136, 136 and 122 of $\mathrm{Cu} / \mathrm{ZnSOD}$, respectively. Using Pymol, a molecular visualization tool, the distances between the predicted interacting amino acid residues were found to be less than 2 angstroms (Figure 3A), suggesting that these amino acid residues are in close spatial proximity, and thus polar bonds can possibly form between these two proteins. Moreover, the predicted amino acid residues within $\mathrm{Cu} /$ $\mathrm{ZnSOD}$ that participate in the complex formation lie very close to the enzymatic active site of $\mathrm{Cu} / \mathrm{ZnSOD}$ [34] (at amino acid positions 47,49,64,81,84,121 [http://www. ncbi.nlm.nih.gov/protein/CAG46542.1]) (Figure 3C). It is therefore probable that the complex formation and the 3-dimensional folding of the proteins hinder the catalytic activity of $\mathrm{Cu} / \mathrm{ZnSOD}$. Moreover, the stability of the docked gelsolin-Cu/ZnSOD complex was analyzed with molecular dynamics simulation that mimics physiological conditions. Molecular dynamics simulation shows that the gelsolin- $\mathrm{Cu} / \mathrm{ZnSOD}$ complex structure remains intact for up to 10 nanoseconds (Figure S3B). Taking together, our in silico analysis suggests that gelsolin and $\mathrm{Cu} / \mathrm{ZnSOD}$ are potential binding partners, and they likely form stable complexes under physiological conditions. Considering the predicted binding site on $\mathrm{Cu} / \mathrm{ZnSOD}$ catalytic site, it is possible that the potential interaction with gelsolin may influence $\mathrm{Cn} / \mathrm{ZnSOD}$ activity.

\section{Gelsolin interacts with Cu/ZnSOD in situ and in vitro}

To validate our in silico analysis, we performed an in situ proximity ligation assay (PLA) as well as coimmunoprecipitation (Co-IP) studies between gelsolin and $\mathrm{Cu} / \mathrm{ZnSOD}$. Permeabilized cells were treated with primary antibodies against gelsolin and $\mathrm{Cu} / \mathrm{ZnSOD}$ 

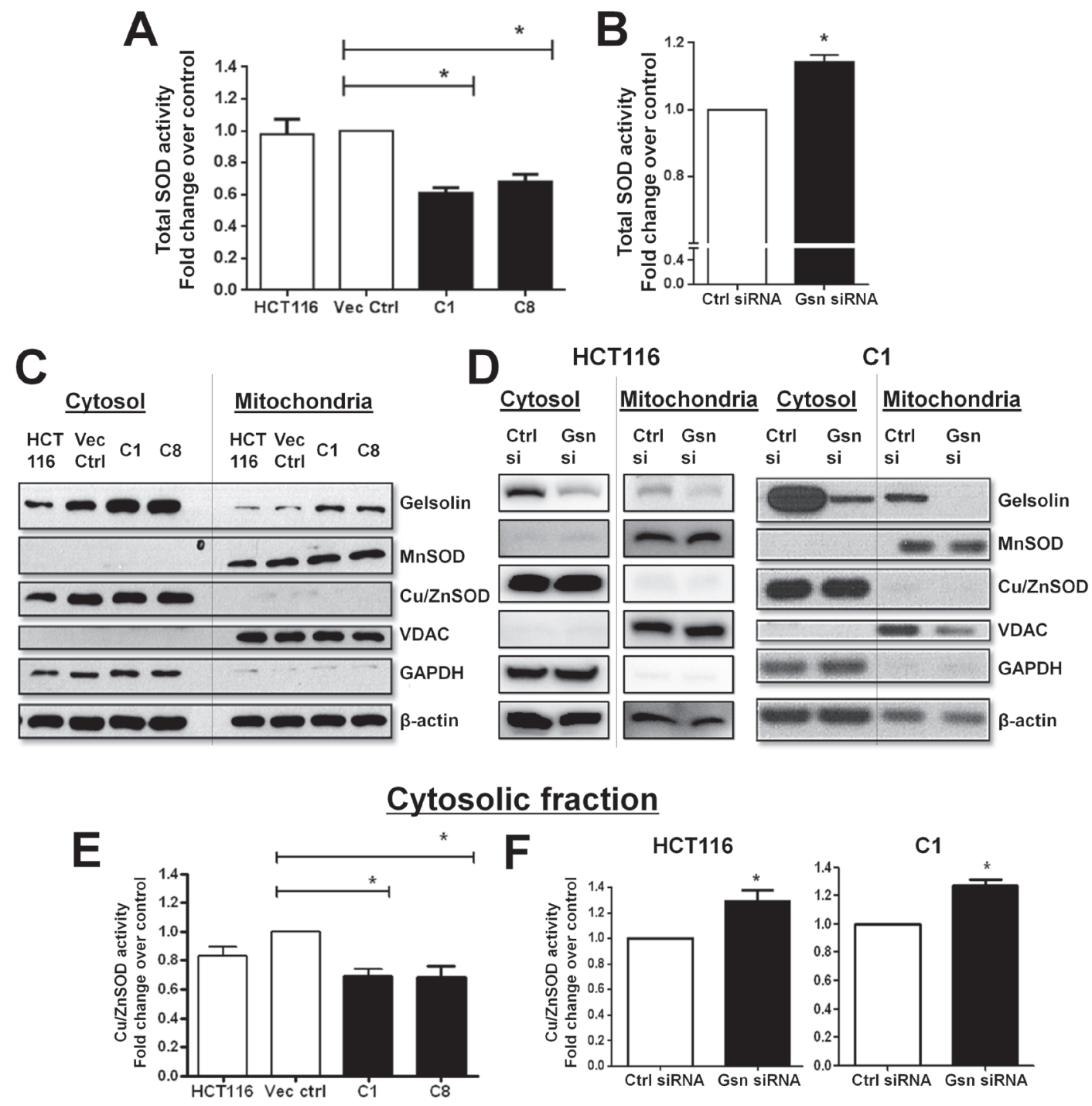

\section{Mitochondrial fraction}

$\mathbf{G}$

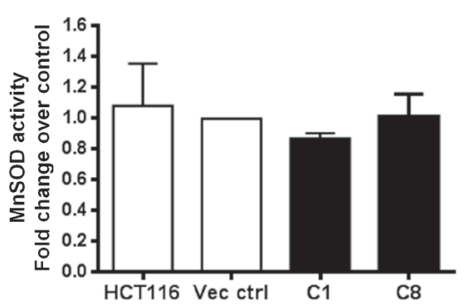

$\mathbf{H}$

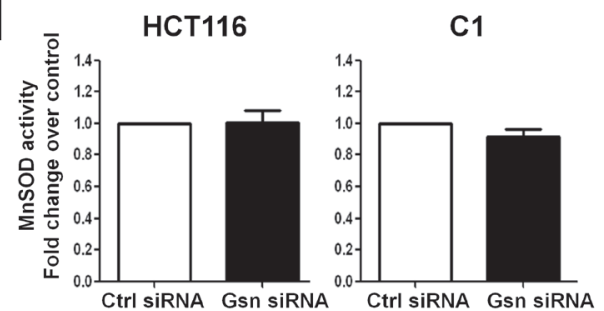

Figure 2: Gelsolin modulates SOD activity. (A \& B) Total intracellular SOD activity was measured from total cell lysates. Increased gelsolin expression lowers the SOD activity in both C1 and C8 cells as compared to wild type HCT116 and empty vector control cells. (B) Knockdown of endogenous gelsolin in HCT116 cells shows increased SOD activity when compared to the control siRNA treated cells. (C \& D) Cytosolic and mitochondrial fractions were isolated in HCT116 cells following either gelsolin overexpression or gelsolin knockdown. Fractionation was confirmed by the presence of MnSOD and VDAC in the mitochondria and $\mathrm{Cu} / \mathrm{ZnSOD}$ and GAPDH in the cytosol. $\beta$-actin was used as the internal loading control. ( $\mathbf{E} \& \mathbf{F}) \mathrm{Cu} / \mathrm{ZnSOD}$ activity was measured from the cytosolic extract. Gelsolin overexpression results in suppression of $\mathrm{Cu} / \mathrm{ZnSOD}$ activity when compared to the empty vector control cells whereas knockdown of gelsolin in HCT116 and $\mathrm{C} 1$ cells results in elevated $\mathrm{Cu} / \mathrm{ZnSOD}$ activity. (G \& $\mathbf{H}$ ) MnSOD activity was determined from the mitochondrial fraction. No significant change in MnSOD activity was observed when gelsolin was overexpressed or silenced in HCT116 and C1 cells. *p-value $<0.05$ versus controls using a two tailed Student's t-test. Values (mean \pm SD ) are expressed as fold over the empty vector control or the control siRNA, which is arbitrarily set as one. The western blot gel pictures are representative images from three independent experiments. 
followed by treatment with secondary antibody probes. The probes are attached to short DNA strands or oligos. If the two proteins interact with each other, the oligos from both the probes ligate, and upon amplification emit a fluorescent signal. The close association between gelsolin and $\mathrm{Cu} / \mathrm{ZnSOD}$ was confirmed upon detection of the PLA signal in red fluorescence, which was visualized using fluorescent microscopy at 563nm (Figure 4A). The intensity of the red signal observed in $\mathrm{C} 1$ cells (overexpressing gelsolin) are higher compared to the vector control cells, thus indicating a greater association between gelsolin and $\mathrm{Cu} / \mathrm{ZnSOD}$. Negative controls such as treatment with isotype antibody and single specific primary antibody (ie. either anti-gelsolin or anti$\mathrm{Cu} / \mathrm{ZnSOD}$ antibody alone) were included to confirm the specificity of the assay. No red fluorescent signals were detected in the negative control sets (Figure S4). Importantly, when we depleted gelsolin expression in $\mathrm{C} 1$ cells, the intensity of the red signal became significantly weaker in gelsolin-knockdown cells, relative to the control siRNA-treated cells (Figure 4B). To further confirm if gelsolin interacts with $\mathrm{Cu} / \mathrm{ZnSOD}$, endogenous $\mathrm{Cu}$ /
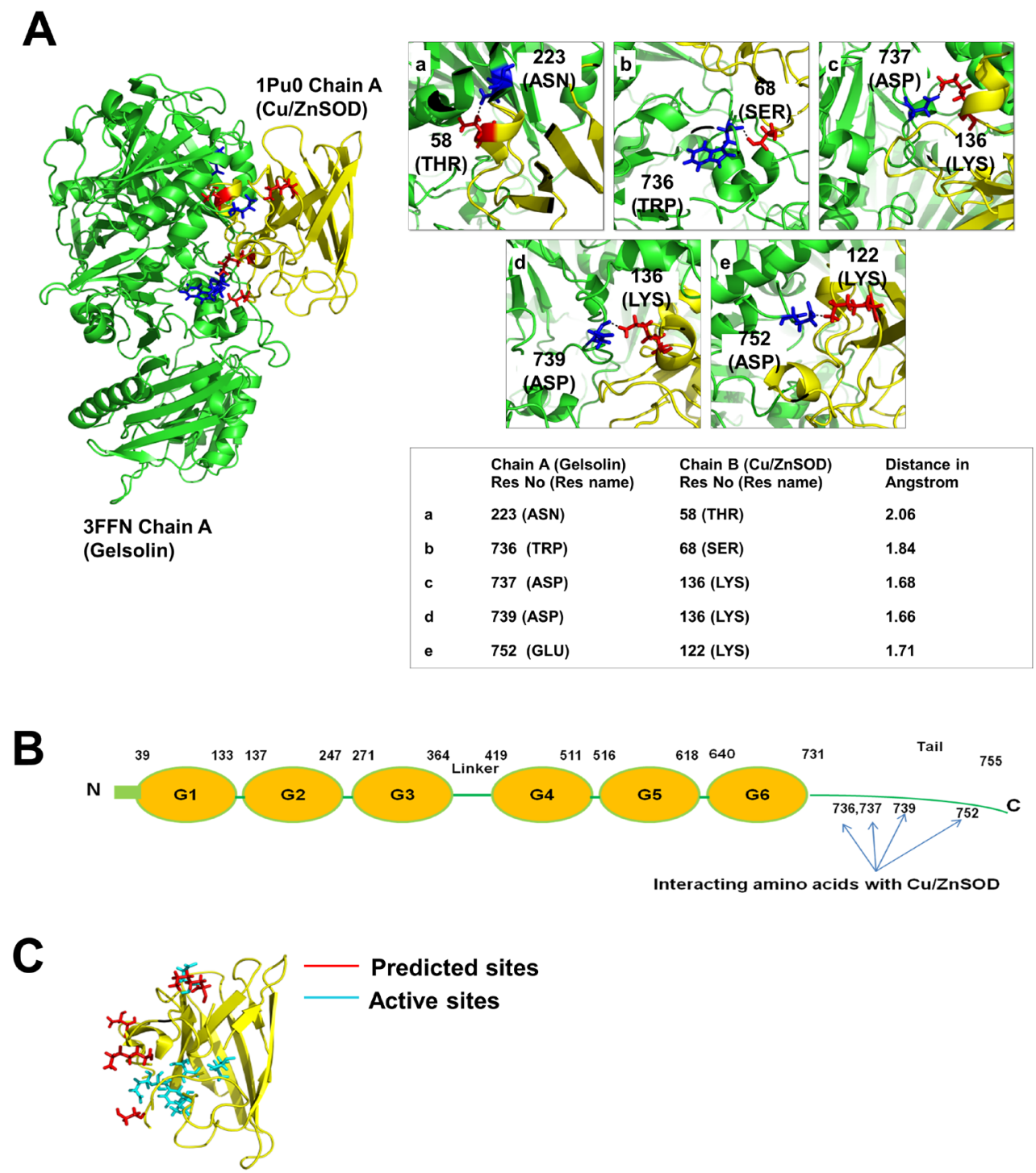

Figure 3: In silico analysis of gelsolin and Cu/ZnSOD interaction. (A) 3-dimensional structure of gelsolin-Cu/ZnSOD complex was obtained using PatchDock analysis. The green structure corresponds to gelsolin (PDB: 3FFN, chain A) and the yellow structure represents the $\mathrm{Cu} / \mathrm{ZnSOD}$ structure (PDB: 1PU0 Chain A). The interacting region of the complex structure of Gelsolin-Cu/ZnSOD was analyzed using PyMol software. The interacting residues were identified and the distance between these residues were calculated and represented in angstrom. (B) Cartoon model of gelsolin structure with domains and the C-terminal tail region. The C-terminal tail region of gelsolin is important for its interaction with $\mathrm{Cu} / \mathrm{ZnSOD}$. Four of the amino acids at positions 736, 737, 739 and 752 of the C-terminal tail region of gelsolin participate in the complex formation with $\mathrm{Cu} / \mathrm{ZnSOD}$. (C) The predicted amino acid residues (positions 58, 68, 136 and 122) of $\mathrm{Cu} / \mathrm{ZnSOD}$ that participate in its interaction with gelsolin lie close to the active sites of the $\mathrm{Cu} / \mathrm{ZnSOD}(47,49,64,81,84,121)$ in the 3-Dimesional structure. 
ZnSOD was immunoprecipitated from the lysate of $\mathrm{C} 1$ cells. The presence of gelsolin in the immunoprecipitate was detected by western blot (Figure 4C), thus confirming that there is physical interaction between the two proteins.
Gelsolin mediates colon cancer cell invasion via modulating the intracellular $\mathrm{O}_{2}^{--}$levels

We have previously shown that increased gelsolin expression promotes colon cancer cell invasion through its involvement in the secretion and increased activiy of uPA [14]. To understand the involvement of gelsolin
A

c1

B

Ctrl si

Gsn si
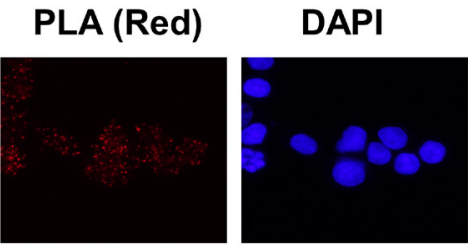

\section{Merged}
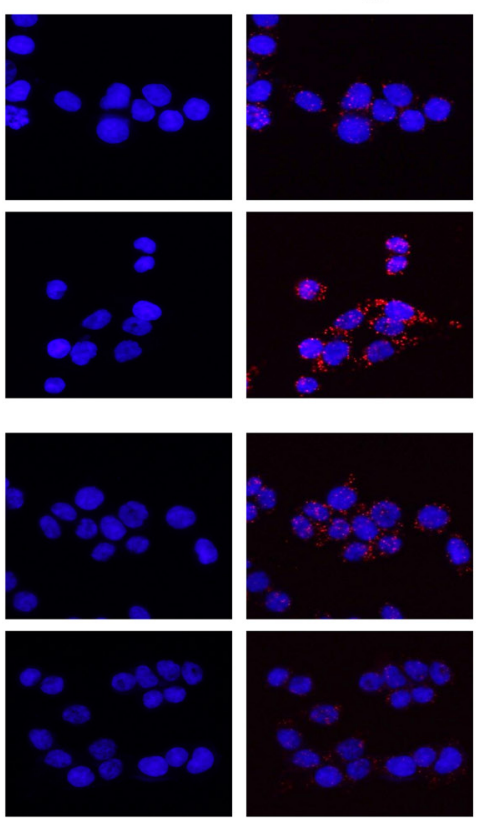

C

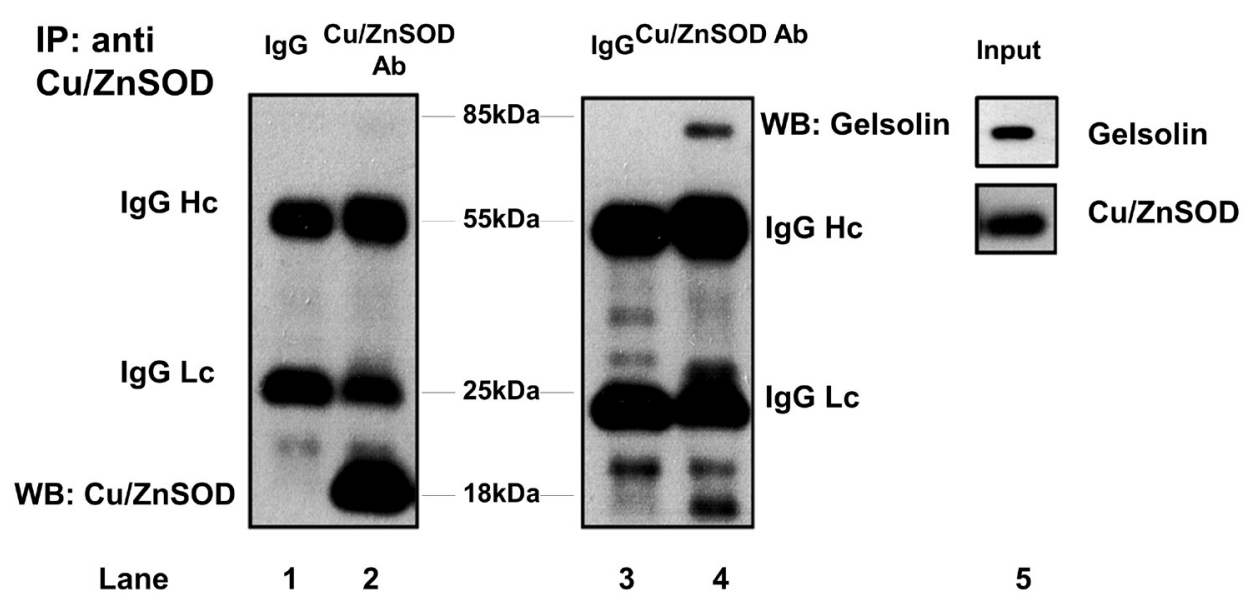

Figure 4: Gelsolin forms a complex with Cu/ZnSOD. (A-B) Proximity ligation assay (PLA) was performed in gelsolinoverexpressing and gelsolin-knockdown cells. PLA signals in red fluorescence were detected when cells were treated with both gelsolin and $\mathrm{Cu} / \mathrm{ZnSOD}$ antibodies. Nuclei were counterstained with DAPI. Images were captured using Olympus DP72 microscope and cellSens software at 40X. (C) Endogenous $\mathrm{Cu} / \mathrm{ZnSOD}$ was immunoprecipitated from lysates of $\mathrm{C} 1$ cells using $\mathrm{Cu} / \mathrm{ZnSOD}$ antibody. $\mathrm{Cu} / \mathrm{ZnSOD}$ and gelsolin were detected in the western blot using specific antibodies against $\mathrm{Cu} / \mathrm{ZnSOD}$ and gelsolin as shown in lanes 2 and 4 . The negative mouse $\mathrm{IgG}$ control in lanes 1 and 3 does not detect any protein band. Lane 5 shows the protein expression of gelsolin and $\mathrm{Cu} / \mathrm{ZnSOD}$ in the $\mathrm{C} 1$ cell lysate. Data shown here is a representative of three independent experiments. 
in uPA-mediated invasion in colorectal cancer in vivo, we analyzed the correlation between gelsolin and uPA gene expression. Based on the microarray data of tumor tissues from Gene Omnibus (GEO), gene expression of gelsolin showed a signifcant positive correlation with uPA in colorectal cancer (Figure 5A). Furthermore, gelsolin expression was found to correlate with several genes involved in epithelial-mesenchymal transition (EMT) (Figure S5), a process promoting invasion [35]. These data strongly support the pro-invasive role of gelsolin in colorectal cancer.
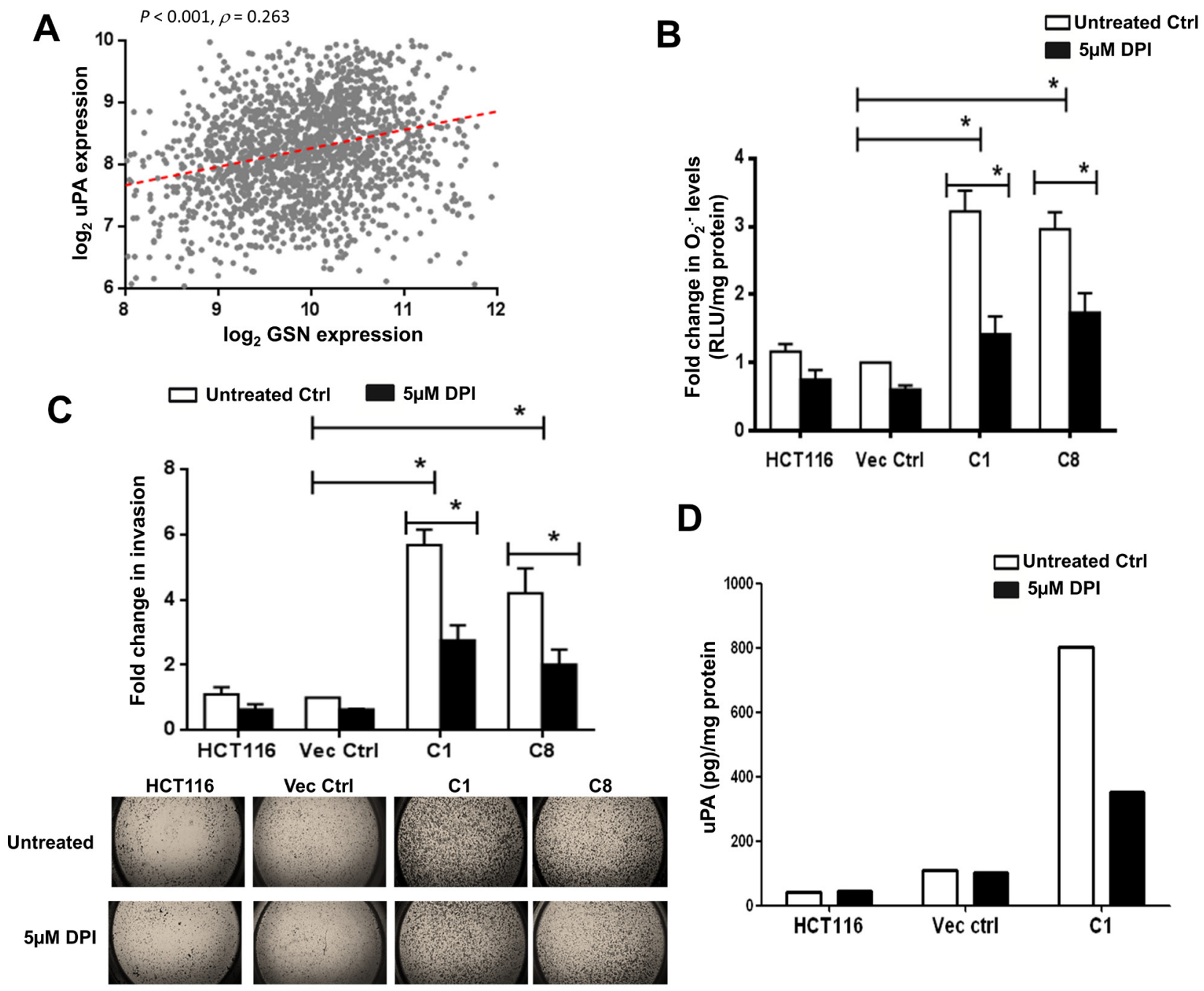

D

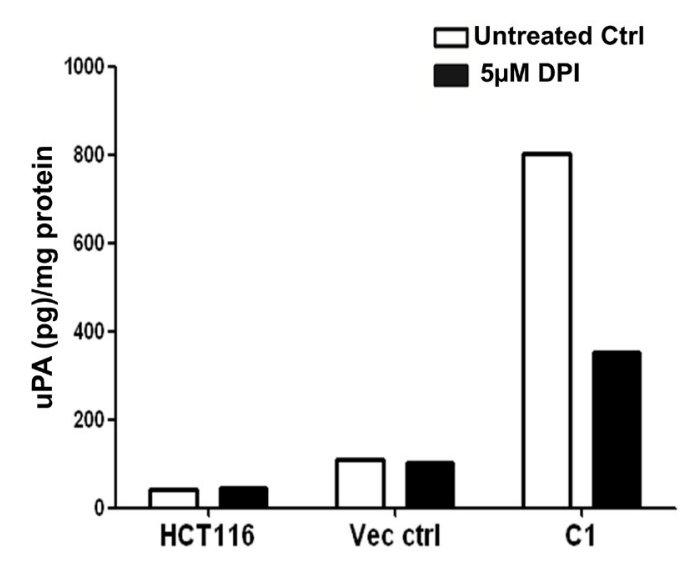

Figure 5: DPI inhibits gelsolin-induced $\mathrm{O}_{2}^{--}$invasion and uPA levels. (A) Correlation of gelsolin expression with uPA across 1820 colorectal cancer samples. Spearman's rank correlation test was used to access the correlation of uPA expression with gelsolin. The correlation coefficient $(\rho)$ and its significance (P value) are indicated. (B-D) Treatment of cells with $5 \mu$ M DPI for 24 hours significantly lowered (B) $\mathrm{O}_{2}{ }^{-}$levels and (C) invasion of gelsolin-overexpresing cells and (D) gelsolin-induced uPA secretion. Upper panel B, quantitative representation of invaded cells following $5 \mu \mathrm{M}$ DPI treatment. Lower panel B, representative pictures of invaded cells with or without DPI treatments are shown (2.5X magnification of the entire well). *p-value $<0.05$ versus controls using a two tailed Student's t-test. Values (mean $\pm \mathrm{SD}$ ) are expressed as fold over the empty vector control, which was arbitrarily set as one. (D) Cells were serum starved with or without $5 \mu \mathrm{M}$ DPI for 8 hours and the conditioned media were used to detect uPA by ELISA. Treatment of cells with $5 \mu \mathrm{M}$ DPI significantly inhibited uPA secretion in the gelsolin-overexpressing $\mathrm{C} 1$ cells whereas $5 \mu \mathrm{M}$ DPI treatment minimally affected uPA secretion in the empty vector control and wild-type HCT116. Secreted uPA levels were normalized to protein concentration. The data shown here is the raw ELISA reading and a representative of three independent experiments. 
overexpressing cells was significantly decreased following DPI treatment (Figure 5C). It should be pointed out that the reduction in invasion observed upon DPI treatment was not due to reduction in cell viability as assessed using the trypan blue dye exclusion method; $5 \mu \mathrm{M}$ DPI for 24 hours had minimal effect on cell viability (Figure S6). We also tested if $\mathrm{O}_{2}-$ participated in enhancing uPA secretion induced by gelsolin. Cells were serum starved with or without $5 \mu \mathrm{M}$ DPI for 8 hours and the conditioned media were used for the detection of UPA by ELISA. Treatment of cells with DPI significantly inhibited uPA secretion in C1 cells, whereas similar treatment had a minimal effect on the empty vector transfected and wild-type HCT116 cells (Figure 5D). We also confirmed that the cell viability was not affected by the DPI treatment (Figure S7). Taken together, these data implicate the role of intracellular $\mathrm{O}_{2}$ in gelsolin-induced tumor cell invasion and uPA secretion.

To confirm the requirement of $\mathrm{O}_{2}^{--}$in tumor cell
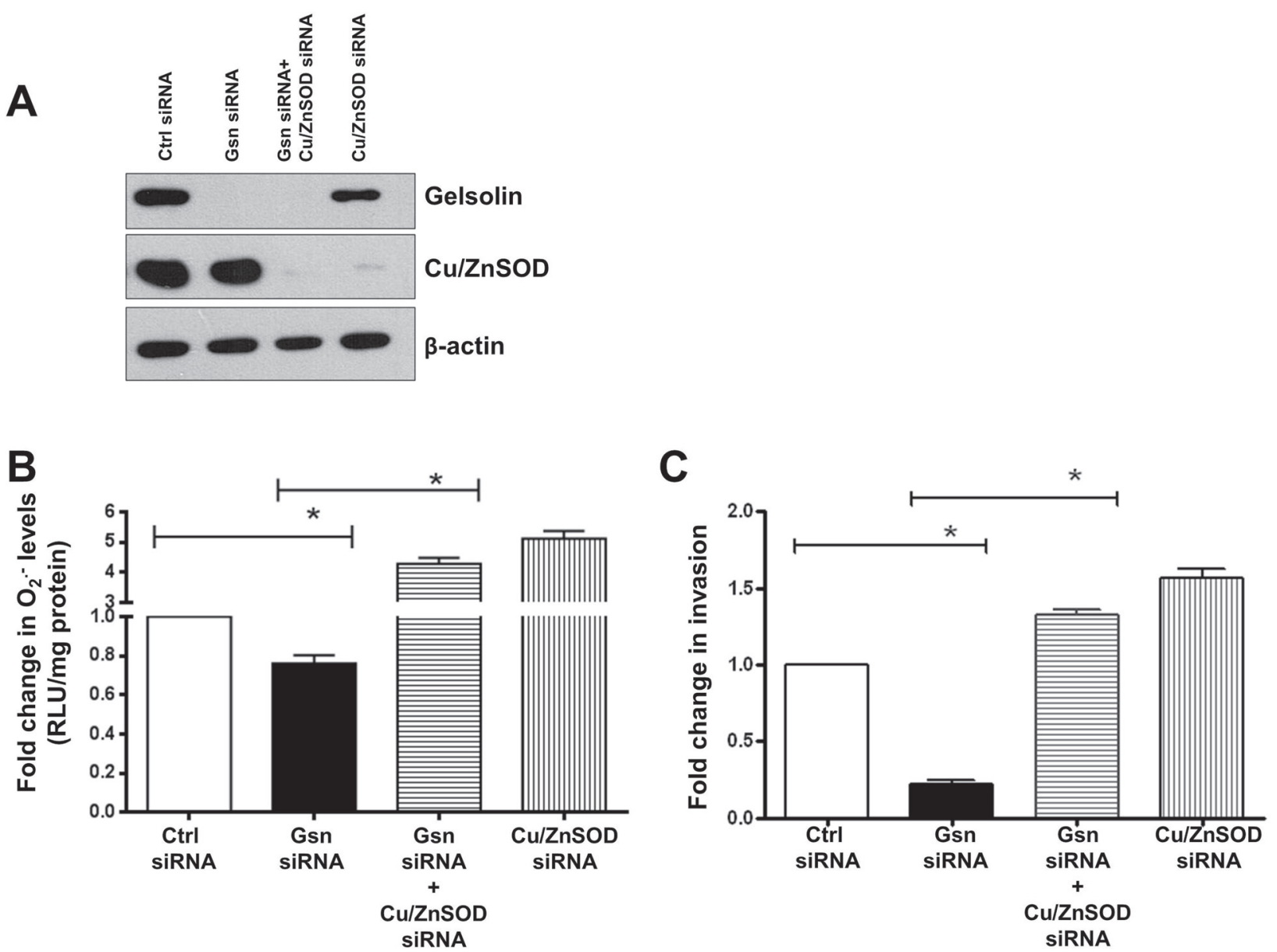

Figure 6: $\mathrm{O}_{2}^{--}$rescues invasion in gelsolin-depleted cells. $\mathrm{O}_{2}{ }^{-}$levels were induced in gelsolin-knockdown cells by silencing $\mathrm{Cu} /$ ZnSOD in wild-type HCT116 cells. (C) Western blot showing knockdown of gelsolin and Cu/ZnSOD in HCT116 cells. (B) Simultaneous knockdown of gelsolin and $\mathrm{Cu} / \mathrm{ZnSOD}$ significantly increases $\mathrm{O}_{2}{ }^{-}$levels in gelsolin-depleted cells. (C) Increasing $\mathrm{O}_{2}{ }^{-}$levels by knockdown of $\mathrm{Cu} / \mathrm{ZnSOD}$ rescues invasion in gelsolin-depleted HCT116 cells. Data shown are mean $\pm \mathrm{SD}$ of at least three independent experiments. *p-value $<0.05$ versus controls using a two tailed Student's $t$-test. Values (mean \pm SD ) are expressed as fold over the empty vector control or the control siRNA, which is arbitrarily set to one. The western blot gel picture is a representative image from three independent experiments. invasion, we asked if an increase in $\mathrm{O}_{2}{ }^{--}$could phenocopy gelsolin had been repressed by siRNA-mediated gene silencing. Therefore, the expression of $\mathrm{Cu} / \mathrm{ZnSOD}$ was silenced by siRNA in gelsolin-depleted cells. Silencing of $\mathrm{Cu} / \mathrm{ZnSOD}$ abrogated the conversion of $\mathrm{O}_{2}{ }^{--}$to $\mathrm{H}_{2} \mathrm{O}_{2}$ thus leading to increased accumulation of $\mathrm{O}_{2}{ }^{-}$even in the absence of gelsolin. Knockdown of gelsolin alone resulted in a decrease in intracellular $\mathrm{O}_{2}{ }^{-}$, however, simultaneous knockdown of gelsolin and $\mathrm{Cu} / \mathrm{ZnSOD}$ restored $\mathrm{O}_{2}^{--}$levels in gelsolin-depleted cells (Figure 6A \& 6B). Similarly, knockdown of gelsolin results in decreased invasion, however, simultaneous knockdown of $\mathrm{Cu} / \mathrm{ZnSOD}$ and gelsolin was able to restore invasion in gelsolin-depleted cells (Figure 6C). These data provide strong evidence to link intracellular $\mathrm{O}_{2}^{--}$to the invasive capacity of tumor cells as well as underpin the requirement of $\mathrm{O}_{2}{ }^{-}$in gelsolininduced cancer cell invasion. the effect of gelsolin in cells where the expression of 


\section{DISCUSSION}

The role of gelsolin in cancer has been controversial due to conflicting evidence suggesting gelsolin's role as a tumor suppressor or activator. The tumor suppressive role of gelsolin is mostly linked to its downregulation in several cancers including breast [37], colon [38], stomach [39], bladder [40], prostate [41], lung [42] as well as in transformed human fibroblast and epithelial cells [43]. Conversely, a number of studies have shown the tumorigenic potential of gelsolin [44-47], including our report on gelsolin's role in inducing uPA secretion to promote tumor cell invasion [14]. In this study, we explored the mechanisms by which gelsolin exert its oncogenic behaviour, specifically in promoting the invasive phenotype. We provide evidence that increased gelsolin expression in HCT116 cells creates a pro-oxidant milieu and promotes tumor cell invasion.

Oxidative stress has been shown to be associated with aggressive phenotypes in cancer cells $[48,49]$ and cancer cell fate decisions are regulated by the cellular redox environment. Whilst a sublethal increase in oxidants may promote cancer cell growth, proliferation and invasion, excessively high oxidative stress is associated with cell and tissue injury and death [50-52]. We show that overexpression of gelsolin generates a sublethal level of oxidative stress that confers an invasive phenotype. Blockade of $\mathrm{O}_{2}-$ production with DPI attenuated the invasive capacities of gelsolin-overexpressing cells as well as lowering gelsolin-induced uPA secretion, implying the critical intermediacy of $\mathrm{O}_{2}^{-}$in gelsolin-induced invasion. In addition to cancer cell invasion, the oncogenic property of $\mathrm{O}_{2}^{-}$has been evidenced through earlier studies that linked oncogene-induced cell survival and proliferation to an increase in intracellular $\mathrm{O}_{2}-[53-56]$. Our findings thus corroborate the oncogenic behavior of $\mathrm{O}_{2}-$ in that it facilitates gelsolin-induced invasion in HCT116 cells.

ROS have been implicated in the alteration of the tumor microenvironment. ROS are well known transcriptional activators of ECM enzymes, such as uPA and MMP family of proteases [57,58]. In addition, ROS can also directly activate MMPs by oxidative modification of the cysteine residue $[59,60]$. However, the effect of intracellular ROS on the enzymatic activity of uPA is not well understood. We have previously reported that gelsolin upregulated the mRNA and protein levels of uPA as well as induced its enzymatic activity [14]. Moreover, our clinical data from colorectal cancer patient gene expression profiles reveals a positive corelation between gelsolin expression and uPA expression, suggesting a clinical significance of gelsolin in promoting cancer invasion. Results presented in this report not only corroborate our earlier findings, but also provide a mechanistic insight into the effect of gelsolin on uPA expression and activity by demonstrating the requirement of intracellular $\mathrm{O}_{2}-$ in gelsolin-induced uPA upregulation. Furthermore, gelsolin- induced uPA secretion and invasion could be dramatically attenuated upon pharmacological inhibition of Nox with DPI. Although, a number of downstream targets of ROS in cancer has been reported, the upstream events that regulate ROS are not well characterized. Our study reveals gelsolin as a novel upstream inducer of $\mathrm{O}_{2}{ }^{-}$in cancer cells as well as provide evidence to link gelsolin-induced invasion to an increase in intracellular $\mathrm{O}_{2}-$. Taken together, our study provides in-depth mechanism in gelsolin-mediated invasion through modulating intracellular $\mathrm{O}_{2}^{-}$levels to enhance UPA secretion and invasion, and this pathway may contribute to invasion and dissemination of cancer in colorectal cancer patient.

By keeping a tight check on the cellular oxidant levels, antioxidants protect cells against oxidant mediated insults. Interestingly, a pro-oxidant intracellular milieu is typically associated with cancer cells, which has been attributed in part to the downregulation of antioxidant defense systems in transformed or malignant cells. For example, downregulation of the three major antioxidants $\mathrm{Cu} / \mathrm{ZnSOD}, \mathrm{MnSOD}$ and catalase have been reported in prostate cancer [61]. On the other hand, overexpression of $\mathrm{Cu} / \mathrm{ZnSOD}, \mathrm{MnSOD}$ and catalase lowered both the growth rate as well as the aggressive nature of breast cancer cells $[48,49]$. SODs act by dismutating $\mathrm{O}_{2}$ to $\mathrm{H}_{2} \mathrm{O}_{2}$ [62], thereby acting as a first line of defense in cells. Whilst the enzymatic functions of the two isoforms of SOD, the cytosolic $\mathrm{Cu} / \mathrm{ZnSOD}$ and mitochondrial MnSOD, are similar, their site of action is restricted by their sub-cellular localization. $\mathrm{Cu} / \mathrm{ZnSOD}$ is responsible for eliminating $\mathrm{O}_{2}{ }^{-}$in the cytosol and MnSOD scavenges $\mathrm{O}_{2}^{-}$in the mitochondria [17]. Our results point to the suppression of cytoplasmic $\mathrm{Cu} / \mathrm{ZnSOD}$ activity, but not of its mitochondrial counterpart, MnSOD, which accounts for the rise in the intracellualr levels of $\mathrm{O}_{2}{ }^{-}$in gelsolin-overexpressing cells. $\mathrm{Cu} / \mathrm{ZnSOD}$ activity is controlled by several factors including copper loading via the chaperone protein CCS (Copper chaperone for $\mathrm{Cu} / \mathrm{ZnSOD}$ ), dimerization of the $\mathrm{Cu} / \mathrm{ZnSOD}$ molecules and structural stability offered by zinc ions $[63,64]$. Besides the biochemical influences, $\mathrm{Cu} / \mathrm{ZnSOD}$ activity is also determined by its transcriptional regulation and protein expression. In this study, we identified gelsolin as a new regulator of $\mathrm{Cu} / \mathrm{ZnSOD}$ by directly interacting with and inhibiting its enzymatic function. Our results were substantiated by in silico analysis, Co-IP as well as PLA data that confirm the existence of a protein-protein interaction between gelsolin and $\mathrm{Cu} / \mathrm{ZnSOD}$ under basal cell culture conditions. Further analysis of this interaction from our in silico data suggested that the predicted amino acid residues of $\mathrm{Cu} / \mathrm{ZnSOD}$ that participate in the complex lie close to the enzymatic active sites of $\mathrm{Cu} / \mathrm{ZnSOD}$. Judging from the docked gelsolin-Cu/ZnSOD complex structure, $\mathrm{Cu} / \mathrm{ZnSOD}$ is positioned in a way that both the predicted interacting amino acid residues and the active sites of $\mathrm{Cu} / \mathrm{ZnSOD}$ (residues 47,49,64,81,84 and 121) 
faced the groove of the relatively bigger gelsolin molecule and perhaps buried itself into this grove. Considering the relative difference in the molecular sizes of gelsolin $(85 \mathrm{Kda})$ and $\mathrm{Cu} / \mathrm{ZnSOD}(18 \mathrm{Kda})$ and the orientation of the molecules, it is plausible that this interaction masks the enzymatic activity of $\mathrm{Cu} / \mathrm{ZnSOD}$, which in turn results in an increase in $\mathrm{O}_{2}{ }^{-}$levels.

Structurally, gelsolin is made up of six domains (G1-G6) that are arranged as tandem repeats [65]. Attached to domain six is the C-terminal tail that plays a pivotal role in regulation of actin binding capability of gelsolin. The C-terminal segment of gelsolin binds to actin in the presence of calcium, while binding of $\mathrm{N}$-terminal segment is controlled by both calcium and the $\mathrm{C}$-terminal tail. In the absence of calcium, however, the tail binds G2 (the second gelsolin repeat present in N-terminal half of gelsolin) and prevents binding to actin $[66,67]$. Calcium is a critical molecule involved in ROS production [6870], however, we did not observe significant differences in calcium levels between vector control and gelsolinoverexpressing cells (Figure S8), indicating that gelsolin may not regulate calcium levels in our model. From our in silico analysis, it is interesting to note that the C-terminal tail region of gelsolin is likely to be crucial in its binding to $\mathrm{Cu} / \mathrm{ZnSOD}$. Interestingly, residues 736, 737, 739 and 752 in gelsolin identified from in silico analysis as potential $\mathrm{Cu} / \mathrm{ZnSOD}$ binding sites all lie at the tail region. Considering the importance of the tail region of gelsolin in its actin-binding regulation, it would be interesting to study if the interaction between gelsolin and $\mathrm{Cu} / \mathrm{ZnSOD}$ could affect the actin-regulation ability of gelsolin. Taken together, in silico analysis of the interaction sites between gelsolin and $\mathrm{Cu} / \mathrm{ZnSOD}$ reveals that the binding may affect the activities of both gelsolin and $\mathrm{Cu} / \mathrm{ZnSOD}$, and it might be interesting to study if the interaction could influence the activities of both proteins which in turn affect the invasive capacity of cancer cells.

In conclusion, our study shows a mechanistic insight into the role of gelsolin in cancer cell invasion. Notably, we have delineated a new role of gelsolin in creating a pro-oxidant milieu that favors tumor cell invasion. We further demonstrate a novel protein-protein interaction between gelsolin and the antioxidant $\mathrm{Cu} / \mathrm{ZnSOD}$, which appears to inhibit $\mathrm{Cu} / \mathrm{ZnSOD}$ activity, leading to increased $\mathrm{O}_{2}{ }^{-}$- levels. Disruption of the gelsolin-Cu/ZnSOD complex by small molecules would restore $\mathrm{Cu} / \mathrm{ZnSOD}$ activity thereby reducing intracellular levels of $\mathrm{O}_{2}{ }_{2}^{-}$which could have potential implications for the design of therapeutic strategies to combat tumor invasive capacity.

\section{MATERIALS AND METHODS}

\section{Cell lines and culture conditions}

Human colorectal cancer cell lines HCT116, RKO, Caco-2 and DLD-1 were obtained from ATCC (Manassas, VA, USA). HCT116 was cultured in McCoy's 5A modified medium; RKO, HeLa and HepG2 cells were cultured in Dulbecco's Modified Eagle's Medium (DMEM). McCoy's 5A and DMEM were purchased from Sigma-Aldrich, LO, USA. Stable HCT116 cell lines overexpressing gelsolin, namely $\mathrm{C} 1$ and $\mathrm{C} 8$ as well as empty vector control cells were grown in McCoy's 5A supplemented with $500 \mu \mathrm{g} /$ mL Geneticin G418 (Gibco, NY, USA). All the media were supplemented with $10 \%$ fetal bovine serum (FBS) (Hyclone, UK). Cells were maintained at $37^{\circ} \mathrm{C}$ in a humidified incubator with $5 \% \mathrm{CO}_{2}$.

\section{Cell transfection}

Stable cell lines overexpressing gelsolin (C1 and C8) were previously derived from HCT116 cells in our laboratory [14].

Two siRNA duplex oligonucleotides AAACGUCCAAUCUUGUUGGAGCAGG and TAGAACTGTCCATATGTGGCAGGGT (Life Technologies, Carlsbad, CA, USA) at 10nM were used to silence the expression of gelsolin, and the oligonucleotides CCATGCAGGTCCTCACTTTA (Qiagen, Hilden, Germany) was used for the silencing of $\mathrm{Cu} / \mathrm{ZnSOD}$ following the manufacturer's protocol. Nontargeting siRNA control with medium GC content (Life Technologies) was used as a negative control for gelsolin, and an all star negative control siRNA (Qiagen) was used as a negative control for $\mathrm{Cu} / \mathrm{ZnSOD}$. To control for double knockdown, cells were treated with both the control siRNAs (medium GC and all star negative).

\section{Determination of intracellular ROS}

Total intracellular superoxide was measured using the chemiluminescence-based lucigenin method as described [71]. Cells were cultured in complete media under normal growth conditions. Pelleted cells were lysed with somatic cell ATP-releasing agent (SigmaAldrich, LO, USA). $400 \mu \mathrm{L}$ of the lysate was immediately transferred to a glass tube and chemiluminescence was monitored using a Berthold Sirius Luminometer. Data were described as Relative Light Units/second/milligram of protein (RLU/s/mg protein). Readings were normalized with protein concentration.

DHE and CM-H 2 DCFDA staining were performed to detect $\mathrm{O}_{2}^{-}$and other $\mathrm{ROS}$ respectively. Cells 
were loaded with either DHE/CM-H DCFDA (Life Technologies) at a final concentration of $10 \mu \mathrm{M}$ at $37^{\circ} \mathrm{C}$ for 10 min and analysis was carried out with flow cytometry (BD Facs Calibur/Cyan ADP Beckman Coulter) with excitation/emission at 488/518nm for CM-H $\mathrm{H}_{2} \mathrm{DCFDA}$ and 530/610nm for DHE. Data were analyzed using the Cell Quest Pro and Summit softwares.

Specific $\mathrm{H}_{2} \mathrm{O}_{2}$ levels in gelsolin-overexpressing cells were analysed using the Amplex Red Hydrogen Peroxide/ Peroxidase Assay Kit (Life Technologies). Cells were lysed and $20 \mu \mathrm{L}$ of cell lysate was dispensed in a well of 96-well plate and Amplex Red reagent mix was added to the samples. Fluorometric reading was immediately determined using Varioskan fluorometric reader at $585 \mathrm{~nm}$. Data was normalized to protein concentration.

\section{Cell viability assay}

Cells were cultured with or without $5 \mu \mathrm{M}$ DPI (Sigma-Aldrich) for $24 \mathrm{~h}$ (in medium containg 1\% FBS) or $8 \mathrm{~h}$ (in serum-free medium). Cells were then trypsinized and number of viable cells were counted using trypan blue exclusion method.

\section{Matrigel invasion assay}

Matrigel invasion assay was performed using the BD Matrigel Basement Membrane Matrix (BD Biosciences, CA, USA $) .40 \mu \mathrm{L}$ of diluted matrigel $(0.33 \mathrm{mg} / \mathrm{mL}$, diluted in serum free media) was coated on a $8-\mu \mathrm{m}$ pore size 6.5-mm diameter transwell filter membrane (Corning, NY, USA). The matrigel was allowed to polymerize at $37^{\circ} \mathrm{C}$ for 2 h. $2 \times 10^{5}$ cells with or without $5 \mu \mathrm{M}$ DPI were seeded on top of the matrigel layer. Complete media containing $10 \%$ FBS was added to the lower chamber as a chemoattractant and incubated for $24 \mathrm{~h}$ at $37^{\circ} \mathrm{C}$. Invaded cells were fixed with $70 \%$ ethanol for $20 \mathrm{~min}$ at room temperature and stained with $0.2 \%$ crystal violet for $30 \mathrm{~min}$ at room temperature. Invaded cells were then captured using Canon powershot A640 camera at 20X magnification for counting. At least ten representative fields were captured per membrane and the number of invaded cells were manually counted using Metamorph software and quantified.

\section{Western blotting}

Cells were lysed with Radioimmunoprecipitation assay buffer (RIPA) (Sigma-Aldrich) supplemented with protease inhibitors (Roche Complete protease inhibitor cocktail, Roche, Basel, Switzerland). Equal amount of lysates were separated by SDS-PAGE and transferred to a polyvinylidene difluoride (PVDF) membrane (Millipore, MA, USA). Membranes were blocked with 5\% w/v milk
(Blocking grade milk, Bio-Rad) for $1 \mathrm{~h}$ and incubated overnight at $4^{\circ} \mathrm{C}$ with primary antibodies against gelsolin (Abcam, UK), Cu/ZnSOD (Cell Signaling, MA, USA), MnSOD (BD), VDAC (Cell Signaling); GAPDH (BD Biosciences) and $\beta$-actin (Sigma-Aldrich). The membranes were washed and incubated with horse radish peroxidaseconjugated secondary antibodies. Signals were visualized using chemiluminescence substrate (Thermo Scientific, MA, USA).

\section{Immunoprecipitation}

Cells were lysed with modified RIPA buffer (5M Nacl, 1M Tris-HCL, pH 8.0, 0.5M EDTA, 1\% Triton $\mathrm{X}-100,0.1 \%$ sodium deoxycholate and protease inhibitors). $500 \mu \mathrm{g}$ of cell lysate was incubated overnight with $20 \mu \mathrm{L}$ of protein A/G agarose beads (Santa Cruz, TX, USA) conjugated to $2 \mu \mathrm{g}$ of primary antibody against $\mathrm{Cu} /$ $\mathrm{ZnSOD}$ at $4^{\circ} \mathrm{C}$. The beads were washed three times with modified RIPA buffer, boiled for $10 \mathrm{~min}$ and the proteins were fractionated by SDS-PAGE followed by western blotting.

\section{In situ proximity ligation assay}

In situ Proximity Ligation Assay (PLA) was performed using the 563 Duolink detection kit (OLINK, Uppsala, Sweden) according to manufacturer's instructions. 1 x $10^{5}$ cells were grown on a 12 -cm coverslip for $24 \mathrm{~h}$. Cells were fixed with 4\% parafolrmaldehyde for $20 \mathrm{~min}$ followed by blocking using 5\% BSA for 1 $\mathrm{h}$ at room temperature. Cells were then incubated with primary antibodies against gelsolin and $\mathrm{Cu} / \mathrm{ZnSOD}$ at $4^{\circ} \mathrm{C}$ overnight. Cells were washed and incubated with the PLA probes at $37^{\circ} \mathrm{C}$ for $1 \mathrm{~h}$. The oligonucleotides were then ligated using the ligation reaction mixture at $37^{\circ} \mathrm{C}$ for $30 \mathrm{~min}$ and the ligated product was amplified using the red fluorescent amplification reagent at $37^{\circ} \mathrm{C}$ for 100 min. Cells were washed and the coverslip was mounted onto a glass slide using mounting media containing DAPI to counterstain the nuclei. Images were captured using Olympus DP72 microscope and cellSens software at 40X and $60 \mathrm{X}$ magnification.

\section{Isolation of intact mitochondria and cytosolic fraction}

Intact mitochondria and cytosolic fractions were isolated as described previously [72]. Cells were grown to $70 \%$ confluence in a $10-\mathrm{cm}$ tissue culture dish. $150 \mu \mathrm{L}$ of mitochondrial extraction buffer $(200 \mathrm{mM}$ mannitol, $68 \mathrm{mM}$ sucrose, 50mM Pipes-KOH pH 7.4, 50mM KCl, $5 \mathrm{mM}$ EGTA, 2mM MgCl2 and $1 \mathrm{mM}$ dithiothreitol), containing protease inhibitors was added to the dishes and 
cells were detached by scraping. The detached cells were transferred to $1.5 \mathrm{~mL}$ tubes and incubated on ice for 20 min. Cells were homogenized with a dounce homogenizer and passaged for 40 strokes followed by centrifugation at $300 \mathrm{~g}$ for $10 \mathrm{~min}$ at $4^{\circ} \mathrm{C}$. The supernatant was transferred to a fresh eppendorf tube and centrifuged at $12000 \mathrm{~g}$ for 30 $\min$ at $4^{\circ} \mathrm{C}$. The pellet contains the intact mitochondrial fraction. The supernatant was again centrifuged at $25,000 \mathrm{~g}$ for $45 \mathrm{~min}$ to obtain the cytosolic fraction.

\section{Superoxide dismutase (SOD) activity assay}

SOD activity was measured using the calorimetricbased SOD activity kit (ENZO Life Sciences, NY, USA) according to the manufacturer's protocol. Cells were lysed and $20 \mu \mathrm{g}$ protein from each sample was dispensed to a clear bottom 96 -well plate. $150 \mu \mathrm{L}$ of WST-1 and Xanthine oxidase (in a master mix) was pipetted into each well and the reaction was then initiated by adding $25 \mu \mathrm{L}$ of $1 \mathrm{X}$ Xanthine Solution. Absorbance reading was obtained at $450 \mathrm{~nm}$ every minute for $10 \mathrm{~min}$ at room temperature. SOD activity of the samples were plotted against SOD standard curve.

\section{In silico prediction of protein-protein interaction}

Molecular Docking: Crystal structures of gelsolin (PDB code: 3FFN, Chain A) and $\mathrm{Cu} / \mathrm{ZnSOD}$ (PDB code: 1PU0, Chain A) were obtained form Protein Data Bank. Molecular docking between Gelsolin and $\mathrm{Cu} / \mathrm{ZnSOD}$ was performed using PatchDock with default cut-off values [73]. PatchDock is a geometry-based molecular docking algorithm, which aims at finding docking confirmations based on the molecular shape complementarity.

Molecular dynamics: Molecular dynamics simulations were performed using the GROMACS version 4.5.3 with OPLS force field [74]. The heterodimer model (Gelsolin-Cu/ZnSOD complex) was placed in a cubic box with the box-edges at least $10 \mathrm{~nm}$ apart from the protein surface. The system was solvated with Simple Point Charge (SPC216) water molecules and appropriate number of counterions was added in the box to neutralize the system. In order to remove the possible clashes between atoms, the energy minimization was set to run for 50000 steps or until convergence to machine precision. After energy minimization, simulations were performed for $100 \mathrm{ps}$ at constant temperature and pressure with periodic boundary conditions, particle-mesh Ewald summation, and a 2-fs time step to heat and equilibrate the system. Then the system was subjected to production of MD simulations for $10 \mathrm{~ns}$. Structures were saved every 2 ps for analysis. The output files from the GROMACS 4.5.3 was analyzed using XMGRACE software. The overall stability of the dimer was measured by estimating the root mean square deviation (RMSD) of the molecule and its radius of gyration $(\mathrm{Rg})$.

Interactions (hydrogen bonds and hydrophobic forces) were analyzed at the interface in each simulated structure. Interactions between hydrophobic side chains are identified using a distance cut off of 5 Angstrom between apolar groups in the apolar side chains [75]. The hydrogen bonds formed between subunits are identified using HBOND program which is a part of JOY suite [76]. The interactions that exist in at least $60 \%$ of the simulated structures were considered as dynamically stable and used for the interpretation of stability.

\section{Data preprocessing of microarray gene expression}

Gene expression microarray data of colon cancer on U133A or U133Plus2 platforms were downloaded from Gene Omnibus (GEO), including GSE10961 ( $\mathrm{n}=$ 18), GSE12945 ( $\mathrm{n}=62)$, GSE13067 ( $\mathrm{n}=74)$, GSE13294 $(\mathrm{n}=155)$, GSE14333 ( $\mathrm{n}=290)$, GSE15960 $(\mathrm{n}=12)$, GSE17536 ( $\mathrm{n}=177)$, GSE17537 $(\mathrm{n}=55), \operatorname{GSE} 18088(\mathrm{n}=$ 53), GSE18105 $(\mathrm{n}=77), \operatorname{GSE} 20916(\mathrm{n}=101), \operatorname{GSE} 23878$ $(\mathrm{n}=35)$, GSE24514 $(\mathrm{n}=34)$, GSE26682 $(\mathrm{n}=331)$, GSE31595 ( $\mathrm{n}=37)$, GSE33113 $(\mathrm{n}=90)$, GSE4045 ( $\mathrm{n}=$ 37), GSE5851 $(\mathrm{n}=80)$, GSE8671 $(\mathrm{n}=32)$, and GSE9348 $(\mathrm{n}=70)$. Robust Multichip Average (RMA) normalization was performed on each dataset. The normalized data was compiled and subsequently standardized using ComBat to remove batch effect [77]. The standardized data yielded a dataset of 1,820 colon carcinoma [78]. A non-parametric test (Spearman's rank correlation) was used to access the correlation and significance of GSN (gelsolin) with other factors.

\section{Sandwiched Enzyme-linked immunosorbent assay (ELISA)}

Cells were cultured in serum free media with or without $5 \mu \mathrm{M}$ DPI for $8 \mathrm{~h}$. Conditioned media was harvested for ELISA. ELISA was performed following standard sandwiched ELISA methods using the uPA DuoSet ELISA kit (R\&D Systems, MN, USA) according to the maufacturer's protocol. ELISA plates were coated with $100 \mu \mathrm{L}$ capture antibody overnight. Wells were then washed thoroughly (3-5 times) with $400 \mu \mathrm{L}$ of wash buffer, followed by blocking the plates with $300 \mu \mathrm{L}$ reagent diluent for $1 \mathrm{~h}$. Wells were washed three times with $1 \mathrm{X}$ wash buffer $(0.05 \%$ PBST). $100 \mu \mathrm{L}$ of samples were dispensed to the wells and incubated for $2 \mathrm{~h}$ at room temperature. Wells were washed and $100 \mu \mathrm{L}$ of Streptavidin-HRP was added to each well and incubated for $20 \mathrm{~min}$ at room temperature. This was followed by adding $100 \mu \mathrm{L}$ of substrate solution and again incubated for $20 \mathrm{~min}$ at room temperature. The reaction was stopped by adding $50 \mu \mathrm{L}$ of $1 \mathrm{M} \mathrm{H}_{2} \mathrm{SO}_{4}$. The optical density of each well was measured using ASYS UVM 340 microplate 
reader at $450 \mathrm{~nm}$, using $570 \mathrm{~nm}$ as reference wavelength.

\section{Microscopy}

Cell counting and images for Invasion assay were obtained using Carl Zeiss Axiovert 40 CFL - Inverted Microscope and images were processed Image J. Visualization and images for the In situ Proximity Ligation Assay were processed using Olympus DP72 microscope and cellSens software.

\section{Intracellular calcium measurement}

Vector control cells and gelsolin-overexpressing cells $(\mathrm{C} 1)$ were were incubated with $5 \mu \mathrm{M}$ Fura2-AM for 30 minutes in calcium buffer $(1.8 \%$ glucose, $2 \%$ BSA, $1 \mathrm{mM} \mathrm{CaCl}, 145 \mathrm{mM} \mathrm{NaCl}, 5 \mathrm{mM} \mathrm{KCl}, 1 \mathrm{mM} \mathrm{MgCl}_{2}$, $10 \mathrm{mM}$ Hepes pH7.4). Cells were then washed twice with calcium buffer and subjected to ratiometric analysis of Fura2-AM fluorescence using Xcellence software under Olympus IX73 fluorescence microscope. Intracellular calcium level was measured by fluorescence ratio of $340 \mathrm{~nm} / 380 \mathrm{~nm}$ (excitation at $340 \mathrm{~nm}$ and $380 \mathrm{~nm}$ and emission at $540 \mathrm{~nm}$ ) at $0.8 \mathrm{~s}$ interval. Average value of $340 \mathrm{~nm} / 380 \mathrm{~nm}$ ratio over 3 minutes was calculated, and the fold changes of ratio compared to vector control cells were calculated.

\section{Statistical analysis}

All statistical analyses were performed using a two tailed Student's $t$-test. Differences between sample means were considered statistically significant when $\mathrm{p}$-value $<$ 0.05 .

\section{ACKNOWLEDGMENTS}

The authors thank Dr. Thai Tran (National University of Singapore) and Ms Yongkang Qiao (National University of Singapore) for their help in calcium measurement.

\section{CONFLICTS OF INTEREST}

The authors have no conflicts of interest to declare.

\section{GRANT SUPPORT}

This work was funded by the National Medical Research Council (NMRC) of Singapore to CTY. APK is supported by grants from the National Medical Research Council of Singapore [R-713-000-177-511], the National Research Foundation Singapore and the Singapore Ministry of Education under its Research Centres of
Excellence initiative to Cancer Science Institute of Singapore, National University of Singapore and by the NCIS Yong Siew Yoon Research Grant through donations from the Yong Loo Lin Trust. SP is supported by grants from the National Medical Research Council and MOE Tier 2.

\section{REFERENCES}

1. Gupta GP and Massague J. Cancer metastasis: building a framework. Cell. 2006; 127(4):679-695.

2. Friedl $\mathrm{P}$ and Alexander S. Cancer invasion and the microenvironment: plasticity and reciprocity. Cell. 2011; 147(5):992-1009.

3. Friedl P and Wolf K. Tumour-cell invasion and migration: diversity and escape mechanisms. Nature reviews Cancer. 2003; 3(5):362-374.

4. Li GH, Arora PD, Chen Y, McCulloch CA and Liu P. Multifunctional roles of gelsolin in health and diseases. Medicinal research reviews. 2012; 32(5):999-1025.

5. Litwin M, Nowak D, Mazur AJ, Baczynska D, Mannherz HG and Malicka-Blaszkiewicz M. Gelsolin affects the migratory ability of human colon adenocarcinoma and melanoma cells. Life sciences. 2012; 90(21-22):851-861.

6. Crowley JL, Smith TC, Fang Z, Takizawa N and Luna EJ. Supervillin reorganizes the actin cytoskeleton and increases invadopodial efficiency. Molecular biology of the cell. 2009; 20(3):948-962.

7. De Corte V, Bruyneel E, Boucherie C, Mareel M, Vandekerckhove J and Gettemans J. Gelsolin-induced epithelial cell invasion is dependent on Ras-Rac signaling. The EMBO journal. 2002; 21(24):6781-6790.

8. Chou J, Stolz DB, Burke NA, Watkins SC and Wells A. Distribution of gelsolin and phosphoinositol 4,5-bisphosphate in lamellipodia during EGF-induced motility. The international journal of biochemistry \& cell biology. 2002; 34(7):776-790.

9. Chen P, Murphy-Ullrich JE and Wells A. A role for gelsolin in actuating epidermal growth factor receptor-mediated cell motility. The Journal of cell biology. 1996; 134(3):689-698.

10. Ridley AJ. Life at the leading edge. Cell. 2011; 145(7):1012-1022.

11. Chellaiah M, Kizer N, Silva M, Alvarez U, Kwiatkowski D and Hruska KA. Gelsolin deficiency blocks podosome assembly and produces increased bone mass and strength. The Journal of cell biology. 2000; 148(4):665-678.

12. Brooks SA, Lomax-Browne HJ, Carter TM, Kinch CE and Hall DM. Molecular interactions in cancer cell metastasis. Acta histochemica. 2010; 112(1):3-25.

13. Meyer T and Hart IR. Mechanisms of tumour metastasis. European journal of cancer. 1998; 34(2):214-221.

14. Zhuo J, Tan EH, Yan B, Tochhawng L, Jayapal M, Koh S, Tay HK, Maciver SK, Hooi SC, Salto-Tellez M, Kumar AP, Goh YC, Lim YC and Yap CT. Gelsolin induces colorectal 
tumor cell invasion via modulation of the urokinasetype plasminogen activator cascade. PloS one. 2012; 7(8):e43594.

15. Halliwell B. Antioxidants in human health and disease. Annual review of nutrition. 1996; 16:33-50.

16. Benhar M, Engelberg D and Levitzki A. ROS, stressactivated kinases and stress signaling in cancer. EMBO reports. 2002; 3(5):420-425.

17. Halliwell B. Oxidative stress and cancer: have we moved forward? The Biochemical journal. 2007; 401(1):1-11.

18. Wu WS. The signaling mechanism of ROS in tumor progression. Cancer metastasis reviews. 2006; 25(4):695705.

19. San Martin A and Griendling KK. Redox control of vascular smooth muscle migration. Antioxidants \& redox signaling. 2010; 12(5):625-640.

20. Tochhawng L, Deng S, Pervaiz S and Yap CT. Redox regulation of cancer cell migration and invasion. Mitochondrion. 2013; 13(3):246-253.

21. Moldovan L, Irani K, Moldovan NI, Finkel $\mathrm{T}$ and Goldschmidt-Clermont PJ. The actin cytoskeleton reorganization induced by Rac1 requires the production of superoxide. Antioxidants \& redox signaling. 1999; 1(1):2943.

22. Suzuki M, Kato M, Hanaka H, Izumi T and Morikawa A. Actin assembly is a crucial factor for superoxide anion generation from adherent human eosinophils. The Journal of allergy and clinical immunology. 2003; 112(1):126-133.

23. Granfeldt D and Dahlgren C. An intact cytoskeleton is required for prolonged respiratory burst activity during neutrophil phagocytosis. Inflammation. 2001; 25(3):165169.

24. Usatyuk PV, Romer LH, He D, Parinandi NL, Kleinberg ME, Zhan S, Jacobson JR, Dudek SM, Pendyala S, Garcia JG and Natarajan V. Regulation of hyperoxia-induced NADPH oxidase activation in human lung endothelial cells by the actin cytoskeleton and cortactin. The Journal of biological chemistry. 2007; 282(32):23284-23295.

25. Zhan Y, He D, Newburger PE and Zhou GW. p47(phox) PX domain of NADPH oxidase targets cell membrane via moesin-mediated association with the actin cytoskeleton. Journal of cellular biochemistry. 2004; 92(4):795-809.

26. Myhre O, Andersen JM, Aarnes $\mathrm{H}$ and Fonnum F. Evaluation of the probes 2',7'-dichlorofluorescin diacetate, luminol, and lucigenin as indicators of reactive species formation. Biochemical pharmacology. 2003; 65(10):15751582.

27. Royall JA and Ischiropoulos $H$. Evaluation of 2',7'-dichlorofluorescin and dihydrorhodamine 123 as fluorescent probes for intracellular $\mathrm{H} 2 \mathrm{O} 2$ in cultured endothelial cells. Archives of biochemistry and biophysics. 1993; 302(2):348-355.

28. Scott JA, Homcy CJ, Khaw BA and Rabito CA. Quantitation of intracellular oxidation in a renal epithelial cell line. Free radical biology \& medicine. 1988; 4(2):7983.

29. Zhu H, Bannenberg GL, Moldeus $\mathrm{P}$ and Shertzer HG. Oxidation pathways for the intracellular probe 2',7'-dichlorofluorescein. Archives of toxicology. 1994; 68(9):582-587.

30. Sies H. Oxidative stress: oxidants and antioxidants. Experimental physiology. 1997; 82(2):291-295.

31. Fridovich I. Superoxide radicals, superoxide dismutases and the aerobic lifestyle. Photochemistry and photobiology. 1978; 28(4-5):733-741.

32. Nag S, Ma Q, Wang H, Chumnarnsilpa S, Lee WL, Larsson M, Kannan B, Hernandez-Valladares M, Burtnick LD and Robinson RC. Ca2+ binding by domain 2 plays a critical role in the activation and stabilization of gelsolin. Proceedings of the National Academy of Sciences of the United States of America. 2009; 106(33):13713-13718.

33. DiDonato M, Craig L, Huff ME, Thayer MM, Cardoso RM, Kassmann CJ, Lo TP, Bruns CK, Powers ET, Kelly JW, Getzoff ED and Tainer JA. ALS mutants of human superoxide dismutase form fibrous aggregates via framework destabilization. Journal of molecular biology. 2003; 332(3):601-615.

34. Banci L, Bertini I, Cramaro F, Del Conte R and Viezzoli MS. The solution structure of reduced dimeric copper zinc superoxide dismutase. The structural effects of dimerization. European journal of biochemistry / FEBS. 2002; 269(7):1905-1915.

35. Lamouille S, Xu J and Derynck R. Molecular mechanisms of epithelial-mesenchymal transition. Nature reviews Molecular cell biology. 2014; 15(3):178-196.

36. Robertson AK, Cross AR, Jones OT and Andrew PW. The use of diphenylene iodonium, an inhibitor of NADPH oxidase, to investigate the antimicrobial action of human monocyte derived macrophages. Journal of immunological methods. 1990; 133(2):175-179.

37. Asch HL, Head K, Dong Y, Natoli F, Winston JS, Connolly $\mathrm{JL}$ and Asch BB. Widespread loss of gelsolin in breast cancers of humans, mice, and rats. Cancer research. 1996; 56(21):4841-4845.

38. Gay F, Estornes Y, Saurin JC, Joly-Pharaboz MO, Friederich E, Scoazec JY and Abello J. In colon carcinogenesis, the cytoskeletal protein gelsolin is downregulated during the transition from adenoma to carcinoma. Human pathology. 2008; 39(10):1420-1430.

39. Moriya S, Yanagihara K, Fujita H and Kuzumaki N. Differential expression of hsp90, gelsolin and gst-pi in human gastric-carcinoma cell-lines. International journal of oncology. 1994; 5(6):1347-1351.

40. Tanaka M, Mullauer L, Ogiso Y, Fujita H, Moriya S, Furuuchi K, Harabayashi T, Shinohara N, Koyanagi T and Kuzumaki N. Gelsolin: a candidate for suppressor of human bladder cancer. Cancer research. 1995; 55(15):3228-3232.

41. Lee HK, Driscoll D, Asch H, Asch B and Zhang PJ. 
Downregulated gelsolin expression in hyperplastic and neoplastic lesions of the prostate. The Prostate. 1999; 40(1):14-19.

42. Dosaka-Akita H, Hommura F, Fujita H, Kinoshita I, Nishi M, Morikawa T, Katoh H, Kawakami Y and Kuzumaki N. Frequent loss of gelsolin expression in non-small cell lung cancers of heavy smokers. Cancer research. 1998; 58(2):322-327.

43. Vandekerckhove J, Bauw G, Vancompernolle K, Honore $\mathrm{B}$ and Celis J. Comparative two-dimensional gel analysis and microsequencing identifies gelsolin as one of the most prominent downregulated markers of transformed human fibroblast and epithelial cells. The Journal of cell biology. 1990; 111(1):95-102.

44. Rao J, Seligson D, Visapaa H, Horvath S, Eeva M, Michel K, Pantuck A, Belldegrun A and Palotie A. Tissue microarray analysis of cytoskeletal actin-associated biomarkers gelsolin and E-cadherin in urothelial carcinoma. Cancer. 2002; 95(6):1247-1257.

45. Shieh DB, Chen IW, Wei TY, Shao CY, Chang HJ, Chung $\mathrm{CH}$, Wong TY and Jin YT. Tissue expression of gelsolin in oral carcinogenesis progression and its clinicopathological implications. Oral oncology. 2006; 42(6):599-606.

46. Thompson CC, Ashcroft FJ, Patel S, Saraga G, Vimalachandran D, Prime W, Campbell F, Dodson A, Jenkins RE, Lemoine NR, Crnogorac-Jurcevic T, Yin HL and Costello E. Pancreatic cancer cells overexpress gelsolin family-capping proteins, which contribute to their cell motility. Gut. 2007; 56(1):95-106.

47. Thor AD, Edgerton SM, Liu S, Moore DH, 2nd and Kwiatkowski DJ. Gelsolin as a negative prognostic factor and effector of motility in erbB-2-positive epidermal growth factor receptor-positive breast cancers. Clinical cancer research. 2001; 7(8):2415-2424.

48. Glorieux C, Dejeans N, Sid B, Beck R, Calderon PB and Verrax J. Catalase overexpression in mammary cancer cells leads to a less aggressive phenotype and an altered response to chemotherapy. Biochemical pharmacology. 2011; 82(10):1384-1390.

49. Weydert CJ, Waugh TA, Ritchie JM, Iyer KS, Smith JL, Li L, Spitz DR and Oberley LW. Overexpression of manganese or copper-zinc superoxide dismutase inhibits breast cancer growth. Free radical biology \& medicine. 2006; 41(2):226-237.

50. Gloire G, Legrand-Poels S and Piette J. NF-kappaB activation by reactive oxygen species: fifteen years later. Biochemical pharmacology. 2006; 72(11):1493-1505.

51. Mellier G and Pervaiz S. The three Rs along the TRAIL: resistance, re-sensitization and reactive oxygen species (ROS). Free radical research. 2012; 46(8):996-1003.

52. Nishikawa M. Reactive oxygen species in tumor metastasis. Cancer letters. 2008; 266(1):53-59.

53. Chen ZX and Pervaiz S. Bcl-2 induces pro-oxidant state by engaging mitochondrial respiration in tumor cells. Cell death and differentiation. 2007; 14(9):1617-1627.

54. Chen ZX and Pervaiz S. Involvement of cytochrome c oxidase subunits $\mathrm{Va}$ and $\mathrm{Vb}$ in the regulation of cancer cell metabolism by Bcl-2. Cell death and differentiation. 2010; 17(3):408-420.

55. Clement MV, Hirpara JL and Pervaiz S. Decrease in intracellular superoxide sensitizes Bcl-2-overexpressing tumor cells to receptor and drug-induced apoptosis independent of the mitochondria. Cell death and differentiation. 2003; 10(11):1273-1285.

56. Pervaiz S, Cao J, Chao OS, Chin YY and Clement MV. Activation of the RacGTPase inhibits apoptosis in human tumor cells. Oncogene. 2001; 20(43):6263-6268.

57. Kim MH, Yoo HS, Kim MY, Jang HJ, Baek MK, Kim HR, Kim KK, Shin BA, Ahn BW and Jung YD. Helicobacter pylori stimulates urokinase plasminogen activator receptor expression and cell invasiveness through reactive oxygen species and NF-kappaB signaling in human gastric carcinoma cells. International journal of molecular medicine. 2007; 19(4):689-697.

58. Tobar N, Villar V and Santibanez JF. ROS-NFkappaB mediates TGF-beta1-induced expression of urokinase-type plasminogen activator, matrix metalloproteinase- 9 and cell invasion. Molecular and cellular biochemistry. 2010; 340(12):195-202.

59. Nelson KK and Melendez JA. Mitochondrial redox control of matrix metalloproteinases. Free radical biology \& medicine. 2004; 37(6):768-784.

60. Saari H, Sorsa T, Lindy O, Suomalainen K, Halinen S and Konttinen YT. Reactive oxygen species as regulators of human neutrophil and fibroblast interstitial collagenases. International journal of tissue reactions. 1992; 14(3):113120.

61. Bostwick DG, Alexander EE, Singh R, Shan A, Qian J, Santella RM, Oberley LW, Yan T, Zhong W, Jiang X and Oberley TD. Antioxidant enzyme expression and reactive oxygen species damage in prostatic intraepithelial neoplasia and cancer. Cancer. 2000; 89(1):123-134.

62. Fridovich I. Superoxide radical and superoxide dismutases. Annual review of biochemistry. 1995; 64:97-112.

63. Furukawa Y, Torres AS and O'Halloran TV. Oxygeninduced maturation of SOD1: a key role for disulfide formation by the copper chaperone CCS. The EMBO journal. 2004; 23(14):2872-2881.

64. Spagnolo L, Toro I, D’Orazio M, O’Neill P, Pedersen JZ, Carugo O, Rotilio G, Battistoni A and Djinovic-Carugo K. Unique features of the sodC-encoded superoxide dismutase from Mycobacterium tuberculosis, a fully functional copper-containing enzyme lacking zinc in the active site. The Journal of biological chemistry. 2004; 279(32):3344733455.

65. Spinardi L and Witke W. Gelsolin and diseases. Sub- 
cellular biochemistry. 2007; 45:55-69.

66. Choe H, Burtnick LD, Mejillano M, Yin HL, Robinson RC and Choe $\mathrm{S}$. The calcium activation of gelsolin: insights from the 3A structure of the G4-G6/actin complex. Journal of molecular biology. 2002; 324(4):691-702.

67. Robinson RC, Mejillano M, Le VP, Burtnick LD, Yin HL and Choe S. Domain movement in gelsolin: a calciumactivated switch. Science. 1999; 286(5446):1939-1942.

68. Banfi B, Molnar G, Maturana A, Steger K, Hegedus B, Demaurex $\mathrm{N}$ and Krause KH. A Ca(2+)-activated NADPH oxidase in testis, spleen, and lymph nodes. The Journal of biological chemistry. 2001; 276(40):37594-37601.

69. Banfi B, Tirone F, Durussel I, Knisz J, Moskwa P, Molnar GZ, Krause KH and Cox JA. Mechanism of Ca2+ activation of the NADPH oxidase 5 (NOX5). The Journal of biological chemistry. 2004; 279(18):18583-18591.

70. Dubiella U, Seybold H, Durian G, Komander E, Lassig R, Witte CP, Schulze WX and Romeis T. Calcium-dependent protein kinase/NADPH oxidase activation circuit is required for rapid defense signal propagation. Proceedings of the National Academy of Sciences of the United States of America. 2013; 110(21):8744-8749.

71. Clement MV and Stamenkovic I. Superoxide anion is a natural inhibitor of FAS-mediated cell death. The EMBO journal. 1996; 15(2):216-225.

72. Low IC, Chen ZX and Pervaiz S. Bcl-2 modulates resveratrol-induced ROS production by regulating mitochondrial respiration in tumor cells. Antioxidants \& redox signaling. 2010; 13(6):807-819.
73. Schneidman-Duhovny D, Inbar Y, Nussinov R and Wolfson HJ. PatchDock and SymmDock: servers for rigid and symmetric docking. Nucleic acids research. 2005; 33(Web Server issue):W363-367.

74. Van Der Spoel D, Lindahl E, Hess B, Groenhof G, Mark $\mathrm{AE}$ and Berendsen HJ. GROMACS: fast, flexible, and free. Journal of computational chemistry. 2005; 26(16):17011718.

75. Tina KG, Bhadra $\mathrm{R}$ and Srinivasan N. PIC: Protein Interactions Calculator. Nucleic acids research. 2007; 35(Web Server issue):W473-476.

76. Mizuguchi K, Deane CM, Blundell TL, Johnson MS and Overington JP. JOY: protein sequence-structure representation and analysis. Bioinformatics. 1998; 14(7):617-623.

77. Johnson WE, Li C and Rabinovic A. Adjusting batch effects in microarray expression data using empirical Bayes methods. Biostatistics. 2007; 8(1):118-127.

78. Tan TZ, Miow QH, Miki Y, Noda T, Mori S, Huang RY and Thiery JP. Epithelial-mesenchymal transition spectrum quantification and its efficacy in deciphering survival and drug responses of cancer patients. EMBO molecular medicine. 2014; 6(10):1279-1293. 